\title{
KRASNOSELSKI-MANN ITERATION FOR HIERARCHICAL FIXED POINTS AND EQUILIBRIUM PROBLEM
}

\author{
GIUSEPPE MARINO ${ }^{凶}$, VITTORIO COLAO, LUIGI MUGLIA \\ and YONGHONG YAO
}

\author{
(Received 30 April 2008)
}

\begin{abstract}
We give an explicit Krasnoselski-Mann type method for finding common solutions of the following system of equilibrium and hierarchical fixed points:

$$
\begin{cases}G\left(x^{*}, y\right) \geq 0, & \forall y \in C, \\ \text { find } x^{*} \in \operatorname{Fix}(T) \text { such that }\left\langle x^{*}-f\left(x^{*}\right), x-x^{*}\right\rangle \geq 0, & \forall x \in \operatorname{Fix}(T),\end{cases}
$$

where $C$ is a closed convex subset of a Hilbert space $H, G: C \times C \rightarrow \mathbb{R}$ is an equilibrium function, $T$ : $C \rightarrow C$ is a nonexpansive mapping with $\operatorname{Fix}(T)$ its set of fixed points and $f: C \rightarrow C$ is a $\rho$-contraction. Our algorithm is constructed and proved using the idea of the paper of [Y. Yao and Y.-C. Liou, 'Weak and strong convergence of Krasnosel'skiı̌-Mann iteration for hierarchical fixed point problems', Inverse Problems 24 (2008), 501-508], in which only the variational inequality problem of finding hierarchically a fixed point of a nonexpansive mapping $T$ with respect to a $\rho$-contraction $f$ was considered. The paper follows the lines of research of corresponding results of Moudafi and Théra.
\end{abstract}

2000 Mathematics subject classification: primary 47H09, 47H10; secondary 58E35.

Keywords and phrases: hierarchical fixed points, equilibrium problem, nonexpansive map, contraction, variational inequality problem, projection.

\section{Introduction}

Let $T, V$ be two nonexpansive mappings from $C$ to $C$, where $C$ is a closed and convex subset of a Hilbert space $H$. Consider the variational inequality problem (VIP) of finding hierarchically a fixed point of a nonexpansive mapping $T$ with respect to another nonexpansive mapping $V$, that is,

$$
\text { find } x^{*} \in \operatorname{Fix}(T) \text { such that }\left\langle x^{*}-V x^{*}, y-x^{*}\right\rangle \geq 0 \quad y \in \operatorname{Fix}(T) .
$$

(Equivalently, $x^{*}=P_{\mathrm{Fix}(T)} V x^{*}-$ that is, $x^{*}$ is a fixed point of the nonexpansive map $P_{\mathrm{Fix}(T)} V$-where for $K$ closed convex subset of $H, P_{K}$ is the metric projection of $H$ on $K$ ).

Supported by Ministero dell'Università e della Ricerca of Italy.

(C) 2009 Australian Mathematical Society 0004-9727/2009 \$16.00 
Of course if $V=I$, the solution set $S$ of (1.1) is just $\operatorname{Fix}(T)$.

The VIP (1.1) covers several topics investigated in literature, among them the following:

(1) (Monotone inclusions) Yamada [32] studies the VIP (1.1) assuming $V=I-\gamma F$, where $\gamma>0$ is sufficiently small and the operator $F$ is Lipschitzian and strongly monotone.

(2) (Convex optimization [4, 23]) Let $\varphi$ be a proper lower semicontinuous convex function on $H$ and let $\psi$ be a convex function on $H$ so that $\nabla \psi$ is strongly monotone. Take

$$
T=\operatorname{prox}_{\lambda \varphi}:=\operatorname{argmin}\left\{\varphi(z)+\frac{1}{2 \lambda}\|\cdot-z\|^{2}\right\} .
$$

Then the VIP (1.1) reduces to the hierarchical minimization problem

$$
\min _{x \in \operatorname{argmin} \varphi} \psi(x)
$$

(3) (Quadratic minimizations over a fixed point set [14]) If $A$ is a linear bounded strongly positive operator on $H, f$ is a $\rho$-contraction on $H$ and $h$ is a potential for $\gamma f$ (that is, $h^{\prime}(x)=\gamma f(x)$ ) where $\gamma>0$ is a constant, consider the minimization problem

$$
\min _{x \in \operatorname{Fix}(T)} \frac{1}{2}\langle A x, x\rangle-h(x) .
$$

The optimality condition to minimize (1.2) is to find a fixed point of $T$ so that

$$
\left\langle(A-\gamma f) x^{*}, x-x^{*}\right\rangle \geq 0, \quad x \in \operatorname{Fix}(T) .
$$

Taking $V=I-\lambda(A-\gamma f)$, where $\gamma>0$ is appropriately chosen so that $V$ is nonexpansive, we find that the previous VIP reduced to (1.1).

(4) Let $A$ be a maximal monotone operator. Take $T=J_{\lambda}^{A}:=(I+\lambda A)^{-1}$ and $V=I-\gamma \nabla \psi$, where $\psi$ is a convex function such that $\nabla \psi$ is $\eta$-Lipschitzian (which is equivalent to the fact that $\nabla \psi$ is $\eta^{-1}$ co-coercive), with $\gamma \in(0,2 / \eta]$ and $\operatorname{Fix}\left(J_{\lambda}^{A}\right)=$ $A^{-1}(0)$. So VIP (1.1) reduces to the mathematical program with generalized equation constraint,

$$
\min _{0 \in A(x)} \psi(x)
$$

considered in [13].

A very particular case of the VIP (1.1) occurs when $V$ is a constant mapping, that is, given $u \in H$,

$$
\text { find } x^{*} \in \operatorname{Fix}(T) \text { such that }\left\langle x^{*}-u, x-x^{*}\right\rangle \geq 0, \quad x \in \operatorname{Fix}(T),
$$

or, equivalently, find the fixed point of $T$ closest to $u$, that is,

$$
x^{*}=P_{\operatorname{Fix}(T)} u=\operatorname{argmin}_{x \in \operatorname{Fix}(T)} \frac{1}{2}\|u-x\|^{2} .
$$


This problem was widely investigated in $[2,9,12,22,26,28,29]$. The explicit method, initiated by Halpern in [9], generates a sequence $\left(x_{n}\right)_{n}$ by iterating

$$
x_{n+1}=\alpha_{n} u+\left(1-\alpha_{n}\right) T x_{n},
$$

where $u, x_{0} \in C$ and $\left(\alpha_{n}\right)_{n} \subset[0,1]$.

The next result is well known.

TheOREM $1.1[2,9,20,21,25-27]$. Assume that $\operatorname{Fix}(T)$ is nonempty. Suppose that the sequence $\left(\alpha_{n}\right)_{n}$ satisfies the following:

(1) $\lim _{n} \alpha_{n}=0$;

(2) $\sum_{n} \alpha_{n}=\infty$;

(3) $\sum_{n}\left|\alpha_{n+1}-\alpha_{n}\right|<\infty$ or $\lim _{n}\left(\left(\alpha_{n+1}-\alpha_{n}\right) / \alpha_{n}\right)=0$.

Then the sequence $\left(x_{n}\right)_{n}$ generated by the algorithm (1.4) converges in norm to $P_{\operatorname{Fix}(T)} u$.

A more general case than $V$ constant is that one $V=f$ with $f$ is a $\rho$-contraction, that is, $\|f(x)-f(y)\| \leq \rho\|x-y\|, \rho \in(0,1)$. In this case we call (1.1) the contractive VIP and the method is also known as viscosity approximation. It was first studied by Moudafi [15] and further developed by Xu [30].

In this method, the explicit scheme (1.4) is replaced by Mann-type scheme

$$
x_{n+1}=\lambda_{n} f\left(x_{n}\right)+\left(1-\lambda_{n}\right) T x_{n}
$$

where $\left(\lambda_{n}\right)_{n}$ is a sequence in $[0,1]$.

THEOREM 1.2 [15,30]. Assume that $\operatorname{Fix}(T)$ is nonempty and let $\left(x_{n}\right)_{n}$ be the sequence by the algorithm (1.5). Assume that:

(1) $\lim _{n} \lambda_{n}=0$;

(2) $\sum_{n} \lambda_{n}=\infty$;

(3) $\sum_{n}\left|\lambda_{n+1}-\lambda_{n}\right|<\infty$ or $\lim _{n}\left(\left(\lambda_{n+1}-\lambda_{n}\right) / \lambda_{n}\right)=0$.

Then $\lim _{n} x_{n}=x^{*}$ exists and $x^{*}$ is the unique solution of the variational inequality

$$
\left\langle(I-f) x^{*}, x-x^{*}\right\rangle \geq 0, \quad x \in \operatorname{Fix}(T) .
$$

Very recently, Yao and Liou [35] replaced the Mann-type scheme (1.5) with the Krasnoselski-Mann type scheme

$$
x_{n+1}=\left(1-\alpha_{n}\right) x_{n}+\alpha_{n}\left(\lambda_{n} f\left(x_{n}\right)+\left(1-\lambda_{n}\right) T x_{n}\right)
$$

and proved the following theorem.

THEOREM 1.3 [35]. Let $C$ be a nonempty closed convex subset of a real Hilbert space $H$. Let $T$ be a nonexpansive mapping of $C$ into itself such that $\operatorname{Fix}(T) \neq \emptyset$. Let $P: C \rightarrow C$ be a $\rho$-contraction. Let $\left(x_{n}\right)_{n}$ be a sequence generated by

$$
x_{n+1}=\left(1-\alpha_{n}\right) x_{n}+\alpha_{n}\left(\sigma_{n} P x_{n}+\left(1-\sigma_{n}\right) T x_{n}\right), \quad n \geq 0 .
$$


Let $\left(\alpha_{n}\right)_{n},\left(\sigma_{n}\right)_{n}$ be two real number sequences in $(0,1)$ satisfying the following conditions:

(i) $0<\liminf _{n \rightarrow \infty} \alpha_{n} \leq \limsup _{n \rightarrow \infty} \alpha_{n}<1$;

(ii) $\lim _{n \rightarrow \infty} \sigma_{n}=0$ and $\sum_{n} \sigma_{n}=\infty$.

\section{Then:}

(1) $\left(x_{n}\right)_{n}$ converges strongly to a fixed point of $T$;

(2) $\quad\left(x_{n}\right)_{n}$ is asymptotically regular, namely $\lim _{n \rightarrow \infty}\left\|x_{n+1}-x_{n}\right\|=0$;

(3) $\left(x_{n}\right)_{n}$ converges strongly to a solution of the problem

$$
\text { find } x^{*} \in \operatorname{Fix}(T) \text { such that }\left\langle x^{*}-f\left(x^{*}\right), x-x^{*}\right\rangle \geq 0, \quad \forall x \in \operatorname{Fix}(T) .
$$

The above scheme is a particular case of the Krasnoselski-Mann algorithm

$$
x_{n+1}=\left(1-\alpha_{n}\right) x_{n}+\alpha_{n}\left(\lambda_{n} V\left(x_{n}\right)+\left(1-\lambda_{n}\right) T x_{n}\right)
$$

with $V$ a nonexpansive mapping, introduced by Moudafi [17].

Some algorithms in signal processing and image reconstruction may be written as the well-known Krasnoselski-Mann (K-M) iteration. The main feature of (K-M)iteration convergence theorems provided a unified framework for analyzing various concrete algorithms. For details, see [3, 5, 31-34].

On the other hand, note that if we put $C=\operatorname{Fix}(T)$ and $G(x, y):=\langle(I-V) x$, $y-x\rangle$, then the VIP (1.1) can be rewritten as

$$
\text { find } x^{*} \in C \text { such that } G\left(x^{*}, y\right) \geq 0, \quad y \in C \text {, }
$$

that is, as an equilibrium problem. More generally, following [6], we can have a countable family of bifunctions from $C \times C$ to $\mathbb{R}$. The basic formulation of this class of problems reduces to solving the system of equilibrium problems

$$
\text { find } x \in C \text { such that } G_{i}(x, y) \geq 0, \quad \forall i \in I, \forall y \in C \text {. }
$$

Blum and Oettli [1, 19] show that, in the case of a single equilibrium problem, the formulation (1.6) covers monotone inclusion problems, saddlepoint problems, VIPs, minimization problems, Nash equilibria in noncooperative games, vector equilibrium problems and certain fixed point problems (see [8]).

It is also worth remarking that, in the case of VIP (1.1), the induced bifunction $G(x, y):=\langle(I-V) x, y-x\rangle$ satisfies the following condition.

CONDITION (1).

(E1) $G(x, x)=0$ for all $x \in H$.

(E2) $G(x, y)+G(y, x) \leq 0$ for all $(x, y) \in H \times H$ (that is, $G$ is monotone).

(E3) For each $x, y, z \in H$,

$$
\limsup _{t \rightarrow 0} G(t z+(1-t) x, y) \leq G(x, y) .
$$

(E4) The function $y \rightarrow G(x, y)$ is convex and lower semicontinuous for each $x \in H$. 
While many methods have been proposed to solve (1.6) (see $[7,10,11,16,18]$ ), we are not aware of so many results for systems of equilibrium problems. For some partial results on these topics see [6].

Here we study a particular case of a system of two equilibrium functions, one induced by a contractive VIP and one satisfying Condition (1), namely

$$
\begin{cases}G\left(x^{*}, y\right) \geq 0, & \forall y \in C, \\ \text { find } x^{*} \in \operatorname{Fix}(T) \text { such that }\left\langle x^{*}-f\left(x^{*}\right), x-x^{*}\right\rangle \geq 0, & \forall x \in \operatorname{Fix}(T) .\end{cases}
$$

Of course such systems include the systems given by a VIP and a contractive VIP.

We show that the following Krasnoselski-Mann-type scheme for the VIP and equilibrium function

$$
\begin{cases}x_{0} \in C, & \\ G\left(u_{n}, y\right)+\frac{1}{r_{n}}\left\langle y-u_{n}, u_{n}-x_{n}\right\rangle \geq 0, & \forall y \in C, \\ x_{n+1}=\left(1-\alpha_{n}\right) x_{n}+\alpha_{n}\left(\lambda_{n} f\left(x_{n}\right)+\left(1-\lambda_{n}\right) T u_{n}\right), & n \geq 1,\end{cases}
$$

solves the system.

\section{Preliminaries}

We give several known results that are fundamental for our proof.

LEMMA 2.1 [24]. Let $\left(x_{n}\right)_{n \in \mathbb{N}}$ and $\left(z_{n}\right)_{n \in \mathbb{N}}$ be bounded sequences in a Banach space $X$ and let $\left(\beta_{n}\right)_{n \in \mathbb{N}}$ be a sequence in $[0,1]$ with $0<\liminf _{n \rightarrow \infty} \beta_{n}$ $\leq \lim \sup _{n \rightarrow \infty} \beta_{n}<1$. Suppose that

$$
x_{n+1}=\beta_{n} x_{n}+\left(1-\beta_{n}\right) z_{n},
$$

for all integers $n \geq 0$, and

$$
\limsup _{n \rightarrow \infty}\left(\left\|z_{n+1}-z_{n}\right\|-\left\|x_{n+1}-x_{n}\right\|\right) \leq 0 .
$$

Then $\lim _{n \rightarrow \infty}\left\|x_{n}-z_{n}\right\|=0$.

LEMMA 2.2 [29]. Assume $\left(a_{n}\right)_{n}$ is a sequence of nonnegative numbers such that

$$
a_{n+1} \leq\left(1-\gamma_{n}\right) a_{n}+\delta_{n}, \quad n \geq 0,
$$

where $\left(\gamma_{n}\right)_{n}$ is a sequence in $(0,1)$ and $\left(\delta_{n}\right)_{n}$ is a sequence in $\mathbb{R}$ such that:

(1) $\sum_{n=1}^{\infty} \gamma_{n}=\infty$;

(2) $\quad \lim _{\sup } \operatorname{sum}_{n \rightarrow \infty} \delta_{n} / \gamma_{n} \leq 0$ or $\sum_{n=1}^{\infty}\left|\delta_{n}\right|<\infty$.

Then $\lim _{n \rightarrow \infty} a_{n}=0$. 
The next lemmas concern the equilibrium function $G$ and the set of equilibrium points

$$
E P(G)=\{x \in C \mid G(x, y) \geq 0, \forall y \in C\} .
$$

LEMMA 2.3 [6]. Let $C$ be a nonempty closed convex subset of $H$ and $G: C \times C \rightarrow \mathbb{R}$ satisfy Condition (1). For $x \in C$ and $r>0$, let $S_{r}: H \rightarrow C$ be the r-resolvent of $G$,

$$
S_{r}(x):=\left\{z \in C \mid G(z, y)+\frac{1}{r}\langle y-z, z-x\rangle \geq 0, \forall y \in C\right\} .
$$

Then $S_{r}$ is well defined and the following hold:

(1) $S_{r}$ is single-valued;

(2) $S_{r}$ is firmly nonexpansive, that is,

$$
\left\|S_{r} x-S_{r} y\right\|^{2} \leq\left\langle S_{r} x-S_{r} y, x-y\right\rangle,
$$

for all $x, y \in H$;

(3) $\operatorname{Fix}\left(S_{r}\right)=E P(G)$;

(4) $\operatorname{EP}(G)$ is closed and convex.

LEMMA 2.4 [6]. Suppose that $G: C \times C \rightarrow \mathbb{R}$ is an equilibrium function satisfying Condition (1). Let $\left(x_{n}\right)_{n \in \mathbb{N}}$ be a sequence in $H$ and $\left(r_{n}\right)_{n \in \mathbb{N}}$ a sequence in $(0,+\infty)$. Define, for all $n \in \mathbb{N}, u_{n}:=S_{r_{n}} x_{n}$ and suppose that $u_{n} \rightarrow p$ and $\left(x_{n}-u_{n}\right) \rightarrow z$. Then $p \in C$ and for all $y \in C, G(p, y)+\langle z, p-y\rangle \geq 0$.

REMARK 2.5. Note that in Lemma 2.4, if $z=0$, then the weak cluster point $p$ for $\left(u_{n}\right)_{n \in \mathbb{N}}$ is a weak cluster point for $\left(x_{n}\right)_{n \in \mathbb{N}}$ and also an equilibrium point for $G$.

Lemma 2.6. Let $G: C \times C \rightarrow \mathbb{R}$ be a bifunction such that Condition (1) holds. Let $\left(w_{n}\right)_{n}$ be a bounded sequence and $z_{n}:=S_{r_{n}} w_{n}$. Let $\left(r_{n}\right)_{n}$ be a sequence of positive numbers such that $\liminf _{n} r_{n}=r>0$. Then there exists a constant $L>0$ such that

$$
\left\|z_{n+1}-z_{n}\right\| \leq\left\|w_{n+1}-w_{n}\right\|+L\left|1-\frac{r_{n}}{r_{n+1}}\right|
$$

PROOF. Since $z_{n}:=S_{r_{n}} w_{n}$ and $z_{n+1}:=S_{r_{n+1}} w_{n+1}$, we obtain that

$$
G\left(z_{n+1}, y\right)+\frac{1}{r_{n+1}}\left\langle y-z_{n+1}, z_{n+1}-w_{n+1}\right\rangle \geq 0, \quad \forall y \in C,
$$

and

$$
G\left(z_{n}, y\right)+\frac{1}{r_{n}}\left\langle y-z_{n}, z_{n}-w_{n}\right\rangle \geq 0, \quad \forall y \in C .
$$

In particular,

$$
G\left(z_{n+1}, z_{n}\right)+\frac{1}{r_{n+1}}\left\langle z_{n}-z_{n+1}, z_{n+1}-w_{n+1}\right\rangle \geq 0
$$


and

$$
G\left(z_{n}, z_{n+1}\right)+\frac{1}{r_{n}}\left\langle z_{n+1}-z_{n}, z_{n}-w_{n}\right\rangle \geq 0 .
$$

Hence, summing up these two inequalities and using (E2),

$$
\frac{1}{r_{n}}\left\langle z_{n+1}-z_{n}, z_{n}-w_{n}\right\rangle+\frac{1}{r_{n+1}}\left\langle z_{n}-z_{n+1}, z_{n+1}-w_{n+1}\right\rangle \geq 0,
$$

so it follows that

$$
\left\langle z_{n+1}-z_{n}, \frac{z_{n}-w_{n}}{r_{n}}-\frac{z_{n+1}-w_{n+1}}{r_{n+1}}\right\rangle \geq 0 .
$$

We derive from (2.2) that

$$
\begin{aligned}
& \left\langle z_{n+1}-z_{n}, z_{n}-w_{n}-\frac{r_{n}}{r_{n+1}}\left(z_{n+1}-w_{n+1}\right)\right\rangle \geq 0 \\
& \Rightarrow\left\langle z_{n+1}-z_{n}, z_{n}-z_{n+1}-w_{n}+z_{n+1}-\frac{r_{n}}{r_{n+1}}\left(z_{n+1}-w_{n+1}\right)\right\rangle \geq 0 \\
& \Rightarrow-\left\|z_{n+1}-z_{n}\right\|^{2}+\left\langle z_{n+1}-z_{n},\left(z_{n+1}-w_{n+1}\right)\left(1-\frac{r_{n}}{r_{n+1}}\right)\right. \\
& \left.\quad+\left(w_{n+1}-w_{n}\right)\right\rangle \geq 0 .
\end{aligned}
$$

Then

$$
\begin{aligned}
\left\|z_{n+1}-z_{n}\right\|^{2} & \leq\left\langle z_{n+1}-z_{n},\left(z_{n+1}-w_{n+1}\right)\left(1-\frac{r_{n}}{r_{n+1}}\right)+\left(w_{n+1}-w_{n}\right)\right\rangle \\
& \leq\left\|z_{n+1}-z_{n}\right\|\left(\left\|w_{n+1}-w_{n}\right\|+\left|1-\frac{r_{n}}{r_{n+1}}\right|\left\|z_{n+1}-w_{n+1}\right\|\right),
\end{aligned}
$$

and so

$$
\left\|z_{n+1}-z_{n}\right\| \leq\left\|w_{n+1}-w_{n}\right\|+\left|1-\frac{r_{n}}{r_{n+1}}\right|\left\|z_{n+1}-w_{n+1}\right\| .
$$

By hypothesis on $\left(r_{n}\right)_{n}$, if $L:=\sup _{n}\left\|z_{n+1}-w_{n+1}\right\|$, we conclude that

$$
\left\|z_{n+1}-z_{n}\right\| \leq\left\|w_{n+1}-w_{n}\right\|+L\left|1-\frac{r_{n}}{r_{n+1}}\right| \text {. }
$$

\section{Main result}

THEOREM 3.1. Let $C$ be a closed convex subset of a Hilbert space H. Let $T: C \rightarrow C$ be a nonexpansive mapping with $\operatorname{Fix}(T) \cap E P(G) \neq \emptyset$. Let $f: C \rightarrow C$ be a $\rho$ contraction. Let $\left(\lambda_{n}\right)_{n}$ be a sequence in $(0,1)$ such that $\lambda_{n} \rightarrow 0$ and $\sum_{n} \lambda_{n}=\infty$. Let $\left(\alpha_{n}\right)_{n}$ be a sequence in $(0,1)$ such that $0<\liminf _{n} \alpha_{n} \leq \lim \sup _{n} \alpha_{n}<1$. 
Let $\left(r_{n}\right)_{n}$ be a sequence of positive real numbers such that $\lim _{n} \inf _{n} r_{n}=r>0$ and $\lim _{n}\left|1-\left(\left(r_{n}\right) /\left(r_{n+1}\right)\right)\right|=0$. Let $\left(x_{n}\right)_{n},\left(u_{n}\right)_{n}$ be the sequences defined by

$$
\begin{cases}x_{0} \in C, & \forall y \in C, \\ G\left(u_{n}, y\right)+\frac{1}{r_{n}}\left\langle y-u_{n}, u_{n}-x_{n}\right\rangle \geq 0, & n \geq 1 . \\ x_{n+1}=\left(1-\alpha_{n}\right) x_{n}+\alpha_{n}\left(\lambda_{n} f\left(x_{n}\right)+\left(1-\lambda_{n}\right) T u_{n}\right), & n \text {. }\end{cases}
$$

Then the sequences both converge to a point $z \in \operatorname{Fix}(T) \cap E P(G)$ which is the unique solution in $\operatorname{Fix}(T) \cap E P(G)$ of the variational inequality

$$
\langle z-f(z), z-x\rangle \leq 0, \quad \forall x \in \operatorname{Fix}(T) \cap E P(G) .
$$

Equivalently, $z=P_{\mathrm{Fix}(T) \cap E P(G)} f z$.

PROOF. Since the inequality

$$
\left\|u_{n}-z\right\|=\left\|S_{r_{n}} x_{n}-S_{r_{n}} z\right\| \leq\left\|x_{n}-z\right\|
$$

holds, we only prove that $x_{n} \rightarrow z$. We divide the proof into several steps.

STEP 1. We prove that the sequence $\left(x_{n}\right)_{n}$ is bounded. Let $v \in \operatorname{Fix}(T) \cap E P(G)$. Then

$$
\begin{aligned}
\left\|x_{n+1}-v\right\|= & \left\|\left(1-\alpha_{n}\right)\left(x_{n}-v\right)+\alpha_{n}\left[\lambda_{n}\left(f\left(x_{n}\right)-v\right)+\left(1-\lambda_{n}\right)\left(T u_{n}-v\right)\right]\right\| \\
\leq & \left(1-\alpha_{n}\right)\left\|x_{n}-v\right\|+\alpha_{n}\left[\lambda _ { n } \left(\left\|f\left(x_{n}\right)-f(v)\right\|\right.\right. \\
& \left.+\|f(v)-v\|)+\left(1-\lambda_{n}\right)\left\|x_{n}-v\right\|\right] \\
\leq & \left(1-\alpha_{n}\right)\left\|x_{n}-v\right\|+\alpha_{n} \lambda_{n} \rho\left\|x_{n}-v\right\| \\
& +\alpha_{n} \lambda_{n}\|f(v)-v\|+\alpha_{n}\left(1-\lambda_{n}\right)\left\|x_{n}-v\right\| \\
= & \left(1-(1-\rho) \lambda_{n} \alpha_{n}\right)\left\|x_{n}-v\right\|+\alpha_{n} \lambda_{n}\|f(v)-v\| \\
\leq & \max \left\{\left\|x_{n}-v\right\|, \frac{\|f(v)-v\|}{1-\rho}\right\} .
\end{aligned}
$$

By induction we obtain that

$$
\left\|x_{n}-v\right\| \leq \max \left\{\left\|x_{0}-v\right\|, \frac{\|f(v)-v\|}{1-\rho}\right\} .
$$

STEP 2. We prove that the sequence $\left(x_{n}\right)_{n}$ is asymptotically regular, that is, $\left\|x_{n}-x_{n+1}\right\| \rightarrow 0$, as $n \rightarrow \infty$. Set $y_{n}=\lambda_{n} f\left(x_{n}\right)+\left(1-\lambda_{n}\right) T u_{n}$ and note that

$$
\begin{aligned}
y_{n+1}-y_{n}= & \lambda_{n+1} f\left(x_{n+1}\right)+\left(1-\lambda_{n+1}\right) T u_{n+1}-\lambda_{n} f\left(x_{n}\right)-\left(1-\lambda_{n}\right) T u_{n} \\
= & \lambda_{n+1}\left(f\left(x_{n+1}\right)-f\left(x_{n}\right)\right)+\left(\lambda_{n+1}-\lambda_{n}\right) f\left(x_{n}\right) \\
& +\left(1-\lambda_{n+1}\right)\left(T u_{n+1}-T u_{n}\right)-\left(\lambda_{n+1}-\lambda_{n}\right) T u_{n} .
\end{aligned}
$$


So, to apply Lemma 2.1 (due to Suzuki), we observe that $x_{n+1}=\alpha_{n} x_{n}+\left(1-\alpha_{n}\right) y_{n}$ and

$$
\begin{aligned}
& \lim \sup \left(\left\|y_{n+1}-y_{n}\right\|-\left\|x_{n+1}-x_{n}\right\|\right) \\
& \stackrel{n}{\leq} \lim \sup \left[\lambda_{n+1}\left\|f\left(x_{n+1}\right)-f\left(x_{n}\right)\right\|+\left|\lambda_{n+1}-\lambda_{n}\right|\left\|f\left(x_{n}\right)-T u_{n}\right\|\right. \\
& \begin{aligned}
& n \\
+ & \left.\left(1-\lambda_{n+1}\right)\left\|T u_{n+1}-T u_{n}\right\|-\left\|x_{n+1}-x_{n}\right\|\right]
\end{aligned} \\
& \leq \lim \sup \left[\lambda_{n+1} \rho\left\|x_{n+1}-x_{n}\right\|+\left|\lambda_{n+1}-\lambda_{n}\right|\left\|f\left(x_{n}\right)-T u_{n}\right\|\right. \\
& \left.+\left(1-\lambda_{n+1}\right)\left\|u_{n+1}-u_{n}\right\|-\left\|x_{n+1}-x_{n}\right\|\right] \\
& \leq \limsup _{n}\left[\lambda_{n+1}\left\|x_{n+1}-x_{n}\right\|+\left(1-\lambda_{n+1}\right)\left(\left\|x_{n+1}-x_{n}\right\|+L\left|1-\frac{r_{n}}{r_{n+1}}\right|\right)\right. \\
& \left.+\left|\lambda_{n+1}-\lambda_{n}\right|\left(\left\|T u_{n}\right\|+\left\|f\left(x_{n}\right)\right\|\right)-\left\|x_{n+1}-x_{n}\right\|\right],
\end{aligned}
$$

where the second inequality holds by (2.1) in Lemma 2.6. By the boundedness of $\left(x_{n}\right)_{n}$ and the hypotheses on the sequences $\left(\lambda_{n}\right)_{n},\left(r_{n}\right)_{n}$ we conclude that

$$
\begin{aligned}
& \underset{n}{\lim \sup }\left(\left\|y_{n+1}-y_{n}\right\|-\left\|x_{n+1}-x_{n}\right\|\right) \\
& \quad \leq \limsup _{n}\left[\left\|x_{n+1}-x_{n}\right\|+L\left|1-\frac{r_{n}}{r_{n+1}}\right|\right. \\
& \left.\quad+\left|\lambda_{n+1}-\lambda_{n}\right|\left(\left\|T u_{n}\right\|+\left\|f\left(x_{n}\right)\right\|\right)-\left\|x_{n+1}-x_{n}\right\|\right] \\
& \quad=\limsup _{n}\left[L\left|1-\frac{r_{n}}{r_{n+1}}\right|+\left|\lambda_{n+1}-\lambda_{n}\right|\left(\left\|T u_{n}\right\|+\left\|f\left(x_{n}\right)\right\|\right)\right]=0 .
\end{aligned}
$$

We can apply Lemma 2.1 to derive

$$
\lim _{n}\left\|x_{n}-y_{n}\right\|=0
$$

On the other hand, a straightforward computation leads to

$$
\lim _{n}\left\|x_{n+1}-x_{n}\right\|=\lim _{n} \alpha_{n}\left\|x_{n}-y_{n}\right\|=0 .
$$

STEP 3. We prove that $\lim _{n}\left\|x_{n}-u_{n}\right\|=0$. First of all we note that, by the firm nonexpansivity of $S_{r_{n}}$, if $p \in E P(G)$, then

$$
\begin{aligned}
\left\|u_{n}-p\right\|^{2} & =\left\langle u_{n}-p, S_{r_{n}} x_{n}-S_{r_{n}} p\right\rangle \leq\left\langle u_{n}-p, x_{n}-p\right\rangle \\
& =\frac{1}{2}\left(\left\|u_{n}-p\right\|^{2}+\left\|x_{n}-p\right\|^{2}-\left\|x_{n}-u_{n}\right\|^{2}\right),
\end{aligned}
$$

from which

$$
\left\|u_{n}-p\right\|^{2} \leq\left\|x_{n}-p\right\|^{2}-\left\|x_{n}-u_{n}\right\|^{2} .
$$


On the other hand, if $v \in \operatorname{Fix}(T) \cap E P(G)$, then

$$
\begin{aligned}
\left\|x_{n+1}-v\right\|^{2}= & \left\|\left(1-\alpha_{n}\right)\left(x_{n}-v\right)+\alpha_{n}\left(\lambda_{n} f\left(x_{n}\right)+\left(1-\lambda_{n}\right) T u_{n}-v\right)\right\|^{2} \\
= & \left\|\left(1-\alpha_{n}\right)\left(x_{n}-v\right)+\alpha_{n}\left(T u_{n}-v\right)+\alpha_{n} \lambda_{n}\left(f\left(x_{n}\right)-T u_{n}\right)\right\|^{2} \\
\leq & \left\|\left(1-\alpha_{n}\right)\left(x_{n}-v\right)+\alpha_{n}\left(T u_{n}-v\right)\right\|^{2} \\
& +2 \lambda_{n}\left\langle f\left(x_{n}\right)-T u_{n}, x_{n+1}-v\right\rangle \\
\leq & \left(1-\alpha_{n}\right)\left\|x_{n}-v\right\|^{2}+\alpha_{n}\left\|T u_{n}-T v\right\|^{2} \\
& +2 \lambda_{n}\left\langle f\left(x_{n}\right)-T u_{n}, x_{n+1}-v\right\rangle \\
\leq & \left(1-\alpha_{n}\right)\left\|x_{n}-v\right\|^{2}+\alpha_{n}\left\|u_{n}-v\right\|^{2} \\
& +2 \lambda_{n}\left\langle f\left(x_{n}\right)-T u_{n}, x_{n+1}-v\right\rangle .
\end{aligned}
$$

Combining (3.5) with (3.6) and setting

$$
z_{n}=2 \lambda_{n}\left\langle f\left(x_{n}\right)-T u_{n}, x_{n+1}-v\right\rangle
$$

leads to

$$
\begin{aligned}
\left\|x_{n+1}-v\right\|^{2} & \leq\left(1-\alpha_{n}\right)\left\|x_{n}-v\right\|^{2}+\alpha_{n}\left(\left\|x_{n}-v\right\|^{2}-\left\|x_{n}-u_{n}\right\|^{2}\right)+z_{n} \\
& \leq\left\|x_{n}-v\right\|^{2}-\alpha_{n}\left\|x_{n}-u_{n}\right\|^{2}+z_{n} .
\end{aligned}
$$

Thus,

$$
\begin{aligned}
\alpha_{n}\left\|x_{n}-u_{n}\right\|^{2} & \leq\left\|x_{n}-v\right\|^{2}-\left\|x_{n+1}-v\right\|^{2}+z_{n} \\
& \leq\left\|x_{n}-x_{n+1}\right\|^{2}+2\left\|x_{n}-x_{n+1}\right\|\left\|x_{n+1}-v\right\|+z_{n} .
\end{aligned}
$$

Since $\left(x_{n}\right)_{n}$ is bounded, $z_{n} \rightarrow 0$. Moreover, by asymptotically regularity of $\left(x_{n}\right)_{n}$ and by the hypothesis on $\left(\alpha_{n}\right)_{n}$, from the latter it follows that

$$
\lim _{n}\left\|x_{n}-u_{n}\right\|=0
$$

as required.

STEP 4. We now prove that the set of weak cluster points $\omega_{w}\left(x_{n}\right)$ is a subset of $\operatorname{Fix}(T) \cap E P(G)$. Let $\left(x_{n_{k}}\right)_{k}$ be a subsequence of $\left(x_{n}\right)_{n}$ weakly converging to a point $p \in C$. Since (3.9) holds, we can apply Lemma 2.4 to ensure that $p$ lies in $E P(G)$.

To show that $p \in \operatorname{Fix}(T)$, we observe that

$$
\begin{aligned}
\left\|x_{n_{k}}-T x_{n_{k}}\right\| \leq & \left\|x_{n_{k}+1}-x_{n_{k}}\right\|+\left\|x_{n_{k}+1}-T u_{n_{k}}\right\|+\left\|T u_{n_{k}}-T x_{n_{k}}\right\| \\
\leq & \left\|x_{n_{k}+1}-x_{n_{k}}\right\|+\left(1-\alpha_{n_{k}}\right)\left\|x_{n_{k}}-T u_{n_{k}}\right\| \\
& +\alpha_{n_{k}} \lambda_{n_{k}}\left\|f\left(x_{n_{k}}\right)-T u_{n_{k}}\right\|+\left\|u_{n_{k}}-x_{n_{k}}\right\|,
\end{aligned}
$$

thus by hypotheses and by Steps 2 and 3 ,

$$
\begin{aligned}
\lim _{k}\left\|x_{n_{k}}-T x_{n_{k}}\right\| \leq & \lim _{k} \frac{\left\|x_{n_{k}+1}-x_{n_{k}}\right\|+\left(2-\alpha_{n_{k}}\right)\left\|u_{n_{k}}-x_{n_{k}}\right\|}{\alpha_{n_{k}}} \\
& +\lambda_{n_{k}}\left\|f\left(x_{n_{k}}\right)-T u_{n_{k}}\right\|=0 .
\end{aligned}
$$


Since $x_{n_{k}} \rightarrow p$, by the demiclosedness principle for nonexpansive mappings [2], we have $p \in \operatorname{Fix}(T)$.

REMARK 3.2. Note that from Step 4 it follows that

$$
\limsup _{n}\left\langle f(z)-z, x_{n}-z\right\rangle \leq 0,
$$

where $z \in \operatorname{Fix}(T) \cap E P(G)$ is the unique solution of the variational inequality (3.2). To show this, let $\left(x_{n_{j}}\right)_{j}$ be such that

$$
\limsup _{n}\left\langle f(z)-z, x_{n}-z\right\rangle=\lim _{j}\left\langle f(z)-z, x_{n_{j}}-z\right\rangle .
$$

By eventually passing to subsequences, we may assume that $x_{n_{j}} \rightarrow p$. Then

$$
\lim _{j}\left\langle f(z)-z, x_{n_{j}}-z\right\rangle=\langle f(z)-z, p-z\rangle \leq 0
$$

since $p \in \operatorname{Fix}(T) \cap E P(G)$.

STEP 5. Finally, we show that $x_{n}, u_{n} \rightarrow z$, as $n \rightarrow \infty$. Since the inequality

$$
\left\|u_{n}-z\right\|=\left\|S_{r_{n}} x_{n}-S_{r_{n}} z\right\| \leq\left\|x_{n}-z\right\|
$$

holds, it is enough to prove that $x_{n} \rightarrow z$ :

$$
\begin{aligned}
\left\|x_{n+1}-z\right\|^{2}= & \left\|\left(1-\alpha_{n}\right)\left(x_{n}-z\right)+\alpha_{n}\left(\lambda_{n} f\left(x_{n}\right)+\left(1-\lambda_{n}\right) T u_{n}-z\right)\right\|^{2} \\
= & \left\|\left(1-\alpha_{n}\right)\left(x_{n}-z\right)+\alpha_{n}\left(1-\lambda_{n}\right)\left(T u_{n}-z\right)+\lambda_{n} \alpha_{n}\left(f\left(x_{n}\right)-z\right)\right\|^{2} \\
\leq & \left\|\left(1-\alpha_{n}\right)\left(x_{n}-z\right)+\alpha_{n}\left(1-\lambda_{n}\right)\left(T u_{n}-z\right)\right\|^{2} \\
& +2 \alpha_{n} \lambda_{n}\left\langle f\left(x_{n}\right)-z, x_{n+1}-z\right\rangle \\
\leq & \left(1-\alpha_{n}\right)\left\|x_{n}-z\right\|^{2}+\alpha_{n}\left(1-\lambda_{n}\right)^{2}\left\|x_{n}-z\right\|^{2} \\
& +2 \alpha_{n} \lambda_{n}\left\langle f\left(x_{n}\right)-z, x_{n+1}-z\right\rangle \\
\leq & \left(1-\alpha_{n}+\alpha_{n}\left(1-\lambda_{n}\right)\right)^{2}\left\|x_{n}-z\right\|^{2} \\
& +2 \alpha_{n} \lambda_{n}\left\langle f\left(x_{n}\right)-f(z), x_{n+1}-z\right\rangle+2 \alpha_{n} \lambda_{n}\left\langle f(z)-z, x_{n+1}-z\right\rangle .
\end{aligned}
$$

The Cauchy-Schwartz inequality gives

$$
\begin{aligned}
2 \alpha_{n} \lambda_{n}\left\langle f\left(x_{n}\right)-f(z), x_{n+1}-z\right\rangle & \leq 2 \alpha_{n} \lambda_{n}\left\|f\left(x_{n}\right)-f(z)\right\|\left\|x_{n+1}-z\right\| \\
& \leq \alpha_{n} \lambda_{n}\left[\left\|f\left(x_{n}\right)-f(z)\right\|^{2}+\left\|x_{n+1}-z\right\|^{2}\right] .
\end{aligned}
$$

So,

$$
\begin{aligned}
\left\|x_{n+1}-z\right\|^{2} \leq & \left(1-\alpha_{n}+\alpha_{n}\left(1-\lambda_{n}\right)^{2}\right)\left\|x_{n}-z\right\|^{2} \\
& \alpha_{n} \lambda_{n}\left(\left\|f\left(x_{n}\right)-f(z)\right\|^{2}+\left\|x_{n+1}-z\right\|^{2}\right) \\
& +2 \alpha_{n} \lambda_{n}\left\langle f(z)-z, x_{n+1}-z\right\rangle \\
\leq & \left(1-\alpha_{n}+\alpha_{n}\left(1-\lambda_{n}\right)^{2}+\alpha_{n} \lambda_{n} \rho\right)\left\|x_{n}-z\right\|^{2} \\
& +\alpha_{n} \lambda_{n}\left\|x_{n+1}-z\right\|^{2}+2 \alpha_{n} \lambda_{n}\left\langle f(z)-z, x_{n+1}-z\right\rangle .
\end{aligned}
$$


We can compute $\left(1-\alpha_{n}+\alpha_{n}\left(1-\lambda_{n}\right)^{2}+\alpha_{n} \lambda_{n} \rho\right)$ and simplify:

$$
\begin{aligned}
\left\|x_{n+1}-z\right\|^{2}= & \left(1-\alpha_{n} \lambda_{n}-\alpha_{n} \lambda_{n}\left(1-\rho-\lambda_{n}\right)\right)\left\|x_{n}-z\right\|^{2} \\
& +\alpha_{n} \lambda_{n}\left\|x_{n+1}-z\right\|^{2}+2 \alpha_{n} \lambda_{n}\left\langle f(z)-z, x_{n+1}-z\right\rangle .
\end{aligned}
$$

Then from the foregoing it follows that

$$
\begin{aligned}
\left\|x_{n+1}-z\right\|^{2} \leq & \left(1-\frac{\alpha_{n} \lambda_{n}\left(1-\rho-\lambda_{n}\right)}{1-\alpha_{n} \lambda_{n}}\right)\left\|x_{n}-z\right\|^{2} \\
& +2 \frac{\alpha_{n} \lambda_{n}}{1-\alpha_{n} \lambda_{n}}\left\langle f(z)-z, x_{n+1}-z\right\rangle .
\end{aligned}
$$

Putting

$$
\begin{aligned}
& a_{n}=\left\|x_{n}-z\right\|^{2}, \\
& \gamma_{n}=\frac{\alpha_{n} \lambda_{n}\left(1-\rho-\lambda_{n}\right)}{1-\alpha_{n} \lambda_{n}}
\end{aligned}
$$

and

$$
\delta_{n}=2 \frac{\alpha_{n} \lambda_{n}}{1-\alpha_{n} \lambda_{n}}\left\langle f(z)-z, x_{n+1}-z\right\rangle,
$$

then (3.11) becomes

$$
a_{n+1} \leq\left(1-\gamma_{n}\right) a_{n}+\delta_{n}
$$

Note that $\lim _{n} \gamma_{n}=0$ and

$$
\limsup _{n} \frac{\delta_{n}}{\gamma_{n}}=\limsup _{n} 2 \frac{\left\langle f(z)-z, x_{n+1}-z\right\rangle}{\left(1-\rho-\lambda_{n}\right)} \leq 0,
$$

by (3.10). Thus we may apply Lemma 2.2 to conclude that

$$
\lim _{n} a_{n}=\lim _{n}\left\|x_{n}-z\right\|=0 .
$$

\section{References}

[1] E. Blum and E. Oettli, 'From optimation and variational inequalities to equilibrium problems', Math. Student 63 (1994), 123-145.

[2] F. E. Browder, 'Convergence of approximation to fixed points of nonexpansive nonlinear mappings in Hilbert spaces', Arch. Ration. Mech. Anal. 24 (1967), 82-90.

[3] C. Byrne, 'A unified treatment of some iterative algorithms in signal processing and image reconstruction', Inverse Problems 20 (2004), 103-120.

[4] A. Cabot, 'Proximal point algorithm controlled by a slowly vanishing term: applications to hierarchical minimization', SIAM J. Optim. 15 (2005), 555-572.

[5] Y. Censor, A. Motova and A. Segal, 'Perturbed projections and subgradient projections for the multiple-sets split feasibility problem', J. Math. Anal. Appl. 327 (2007), 1244-1256.

[6] P. L. Combettes and S. A. Hirstoaga, 'Equilibrium programming in Hilbert spaces', J. Nonlinear Convex Anal. 6(1) (2005), 117-136.

[7] S. D. Flåm and A. S. Antipin, 'Equilibrium programming using proximal-like algorithms', Math. Program. 78 (1997), 29-41. 
[8] A. Göpfert, H. Riahi, C. Tammer and C. Zălinescu, Variational Methods in Partially Ordered Spaces (Springer, New York, 2003).

[9] B. Halpern, 'Fixed points of nonexpansive maps', Bull. Amer. Math. Soc. 73 (1967), 957-961.

[10] A. N. Iusem and W. Sosa, 'Iterative algorithms for equilibrium problems', Optimization 52 (2003), 301-316.

[11] I. V. Konnov, 'Application of the proximal point method to nonmonotone equilibrium problems', J. Optim. Theory Appl. 119 (2003), 317-333.

[12] P. L. Lions, 'Approximation de points fixes de contractions', C. R. Acad. Sci. Sér. A-B Paris 284 (1977), 1357-1359.

[13] Z.-Q. Luo, J.-S. Pang and D. Ralph, Mathematical Programs with Equilibrium Constraints (Cambridge University Press, Cambridge, 1996).

[14] G. Marino and H. K. Xu, 'A general iterative method for nonexpansive mappings in Hilbert spaces', J. Math. Anal. Appl. 318(1) (2006), 43-52.

[15] A. Moudafi, 'Viscosity approximation methods for fixed-points problems', J. Math. Anal. Appl. 241 (2000), 46-55.

[16] - 'Second-order differential proximal methods for equilibrium problems', J. Inequal. Pure Appl. Math. 4 (2003), art. 18.

[17] _ ' Krasnoselski-Mann iteration for hierarchical fixed-point problems', Inverse Problems $\mathbf{2 3}$ (2007), 1635-1640.

[18] A. Moudafi and M. Théra, 'Proximal and dynamical approaches to equilibrium problems', in: Ill-Posed Variational Problems and Regularization Techniques, Lecture Notes in Economics and Math. Sys., 477 (Springer, New York, 1999).

[19] W. Oettli, 'A remark on vector-valued equilibria and generalized monotonicity', Acta Math. Vietnamica 22 (1997), 215-221.

[20] S. Reich, 'Strong convergence theorems for resolvents of accretive operators in Banach spaces', J. Math. Anal. Appl. 75 (1980), 287-292.

[21] _ 'Approximating fixed points of nonexpansive mappings', Panamerican. Math. J. 4(2) (1994), 23-28.

[22] N. Shioji and W. Takahashi, 'Strong convergence of approximated sequeces for nonexpansive mappings in Banach spaces', Proc. Amer. Math. Soc. 125 (1997), 3641-3645.

[23] M. Solodov, 'An explicit descent method for bilevel convex optimization', J. Convex Anal. 14 (2007), 227-237.

[24] T. Suzuki, 'Strong convergence of Krasnoselskii and Mann's type sequences for one-parameter nonexpansive semigroups without Bochner integrals', J. Math. Anal. Appl. 305(1) (2005), 227-239.

[25] R. Wittmann, 'Approximation of fixed points of nonexpansive mappings', Arch. Math. 58 (1992), 486-491.

[26] H. K. Xu, 'Iterative algorithms for nonlinear operators', J. London Math. Soc. 66 (2002), 240-256.

[27] - 'Another control condition in an iterative method for nonexpansive mappings', Bull. Austral. Math. Soc. 65 (2002), 109-113.

[28] - 'Remarks on an iterative method for nonexpansive mappings', Comm. Appl. Nonlinear Anal. 10(1) (2003), 67-75.

[29] , 'An iterative approach to quadratic optimization', J. Optim. Theory Appl. 116(3) (2003), $659-678$.

[30] - 'Viscosity approximation methods for nonexpansive mappings', J. Math. Anal. Appl. 298 (2004), 279-291.

[31] _ 'A variable Krasnoselski-Mann algorithm and the multiple-set split feasibility problem', Inverse Problems 22 (2006), 2021-2034.

[32] I. Yamada, 'The hybrid steepest descent method for the variational inequality problem over the intersection of fixed point sets of nonexpansive mappings', in: Inherently Parallel Algorithm for Feasibility and Optimization and their Applications (eds. D. Butnariu, Y. Censor and S. Reich) (Elsevier, 2001), pp. 473-504. 
[33] I. Yamada, N. Ogura and N. Shirakawa, 'A numerically robust hybrid steepest descent method for the convexity constrained generalized inverse problems', Contemp. Math. 313 (2002), 269-305.

[34] Q. Yang and J. Zhao, 'Generalized KM theorems and their applications', Inverse Problems 22 (2006), 833-844.

[35] Y. Yao and Y.-C. Liou, 'Weak and strong convergence of Krasnosel'skiı̌-Mann iteration for hierarchical fixed point problems', Inverse Problems 24 (2008), 501-508.

GIUSEPPE MARINO, Dipartimento di Matematica, Università della Calabria, 87036, Arcavacata di Rende (CS), Italy

e-mail: gmarino@unical.it

VITTORIO COLAO, Dipartimento di Matematica, Università della Calabria, 87036, Arcavacata di Rende (CS), Italy

e-mail: colao@mat.unical.it

LUIGI MUGLIA, Dipartimento di Matematica, Università della Calabria, 87036, Arcavacata di Rende (CS), Italy

e-mail: muglia@mat.unical.it

YONGHONG YAO, Department of Mathematics, Tianjin Polytechnic University, Tianjin 300160, People's Republic of China

e-mail: yaoyonghong@yahoo.cn 